\title{
Vascular injuries after minor blunt upper extremity trauma: pitfalls in the recognition and diagnosis of potential "near miss" injuries Jonathan T Bravman ${ }^{1}$, Kyros Ipaktchi ${ }^{1}$, Walter L Biffl ${ }^{2}$ and Philip F Stahel ${ }^{* 1}$
}

Address: ${ }^{1}$ Department of Orthopaedic Surgery, Denver Health Medical Center, University of Colorado School of Medicine, 777 Bannock Street, Denver, CO 80204, USA and 2Department of Surgery, Denver Health Medical Center, University of Colorado School of Medicine, 777 Bannock Street, Denver, CO 80204, USA

Email: Jonathan T Bravman - jonathan.bravman@uchsc.edu; Kyros Ipaktchi - kyros.ipaktchi@dhha.org; Walter L Biffl - walter.biffl@dhha.org; Philip F Stahel* - philip.stahel@dhha.org

* Corresponding author

Published: 25 November 2008

Scandinavian Journal of Trauma, Resuscitation and Emergency Medicine 2008, 16:16 doi:10.1 186/1757-724I-16-16
Received: 17 October 2008

Accepted: 25 November 2008

This article is available from: http://www.sjtrem.com/content//6/1/16

(C) 2008 Bravman et al; licensee BioMed Central Ltd.

This is an Open Access article distributed under the terms of the Creative Commons Attribution License (http://creativecommons.org/licenses/by/2.0), which permits unrestricted use, distribution, and reproduction in any medium, provided the original work is properly cited.

\begin{abstract}
Background: Low energy trauma to the upper extremity is rarely associated with a significant vascular injury. Due to the low incidence, a high level of suspicion combined with appropriate diagnostic algorithms are mandatory for early recognition and timely management of these potentially detrimental injuries.

Methods: Review of the pertinent literature, supported by the presentation of two representative "near miss" case examples.

Results: A major diagnostic pitfall is represented by the insidious presentation of significant upper extremity arterial injuries with intact pulses and normal capillary refill distal to the injury site, due to collateral perfusion. Thus, severe vascular injuries may easily be missed or neglected at the upper extremity, leading to a long-term adverse outcome with the potential need for a surgical amputation.

Conclusion: The present review article provides an outline of the diagnostic challenges related to these rare vascular injuries and emphasizes the necessity for a high level of suspicion, even in the absence of a significant penetrating or high-velocity trauma mechanism.
\end{abstract}

\section{Background}

Upper extremity arterial injuries secondary to minor, nonpenetrating trauma mechanisms, such as low energy traumatic joint dislocations, are very rare. In a study of 1,565 upper extremity dislocations, arterial lesions were detected in $0.97 \%$ and $0.47 \%$ of all cases with closed shoulder or elbow dislocations, respectively [1]. Interestingly, this rare entity has been first described in the French literature almost 100 years ago, and was found to be associated with a high mortality due to delayed recognition and a lack of effective treatment strategies [2]. Elderly patients appear to be particularly susceptible to vascular injuries due to loss of arterial elasticity [3]. In this article, we outline the diagnostic challenges related to these rare vascular injuries, based on the description of two clinical "near miss" cases, and provide an updated review of the pertinent literature.

\section{"Near miss" case \#I}

A 46 year-old right hand dominant male presented to our emergency department (ED) after sustaining a fall from standing height off a curb while intoxicated. The patient 
had a history of recurrent right shoulder dislocations after low-energy mechanisms. He has been previously treated conservatively at outside facilities, with closed reduction and temporary immobilization. On current presentation to the ED, the patient complained of right shoulder pain. Clinically, he had a typical deformity consistent with an anterior shoulder dislocation. This diagnosis was confirmed by plain x-rays (Fig. 1A). Neurovascular exam demonstrated normal $(2+)$ and symmetric radial pulses with $5 / 5$ motor function and fully intact light touch sensation and 2-point discrimination in the distribution of the radial, median, and ulnar nerves. Conscious sedation was administered and closed reduction was carried out uneventfully in the ED, by a Kocher maneuver (Fig. 1B). The post-reduction exam revealed an unchanged neurovascular exam, and the plan was made for patient discharge with elective follow-up in orthopedic clinic. Shortly before discharge, the new finding of a "pectoral swelling" was noted. At this time, the orthopedic surgery service was consulted for concern of a potential pectoralis muscle rupture. Upon the repeat evaluation by the orthopedic team, an expanding hematoma was appreciated in the axilla and anterolateral chest wall. Additionally, compared to the previously documented exam, a change in neurologic status was noted with a decrease in light touch sensation in the distribution of the median and ulnar nerve, while motor function remained intact. In addition, the right arm was found to have a mildly hyperemic appearance. Distal pulses were present and palpable, and the arm-arm arterial index was measured to be 1.1 (i.e. ipsilateral blood pressure compared to the contralateral side). Based on the neurological finding of a "soft sign" for arterial injury (Table 1), a concern for arterial injury was raised, and a further diagnostic work-up was initiated. An emergent angiography was performed, which revealed a leak-

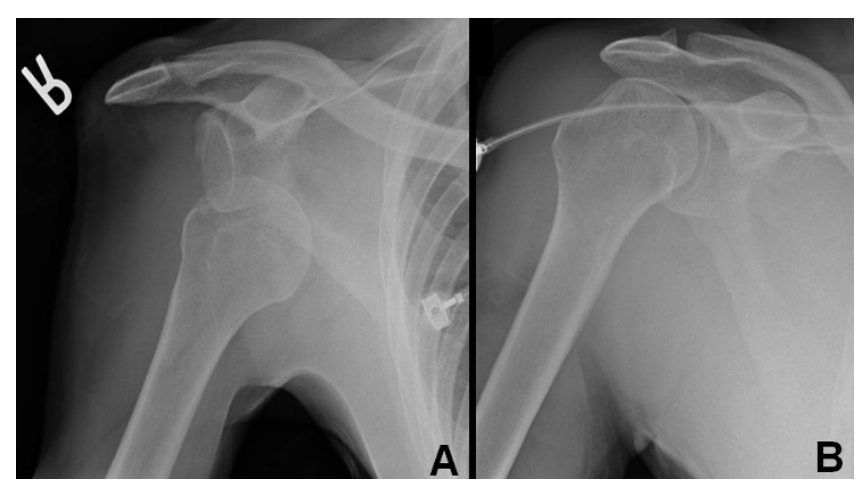

Figure I

Case demonstration of a 46-year-old right hand dominant male who sustained a fall from standing onto the right shoulder. Injury X-ray demonstrates an anterior shoulder dislocation (panel $A$ ) which was successfully reduced in the emergency department (panel B). ing pseudoaneurysm of the right axillary artery (Fig 2, arrow). The vascular surgery team was consulted and the patient was immediately taken to the operating room. The surgical exploration revealed an avulsion injury to two posterior and inferiorly directed branches from the base of the circumflex humeral artery with extension into the axillary artery. These branches were ligated and a primary repair of the remaining axillary artery defect was performed. Forearm fasciotomies were performed to prevent an ischemia/reperfusion-mediated compartment syndrome. The vascular repair was successful, and the patient recovered well secondary to a repeat return to the OR for wound closure of the fasciotomy incisions. On final follow-up in orthopedic clinic, the patient had an intact neurologic exam and well perfused right arm, with strong palpable symmetric radial pulses.

\section{"Near miss" case \#2}

A 38 year-old right hand dominant woman presented to the ED intoxicated, one day after being assaulted. Per the patient's report, her left arm had been twisted during the altercation. She complained of left arm pain. Her past medical history was relevant for chronic alcohol abuse. On first evaluation, the left arm appeared cooler than the right arm, and there was a gross deformity and instability at the elbow joint with an ecchymotic area over the medial side of the elbow (Fig 3A). Clinically, the patient had a normal perfusion in her left hand (Fig. 3B). Her neurologic evaluation revealed an intact 5/5 motor function of the left hand and intact sensation to light touch and 2point discrimination. The radial pulse was symmetrically palpable $(2+)$. The patient was radiographically found to have a traumatic elbow dislocation (Fig. 4A), which was

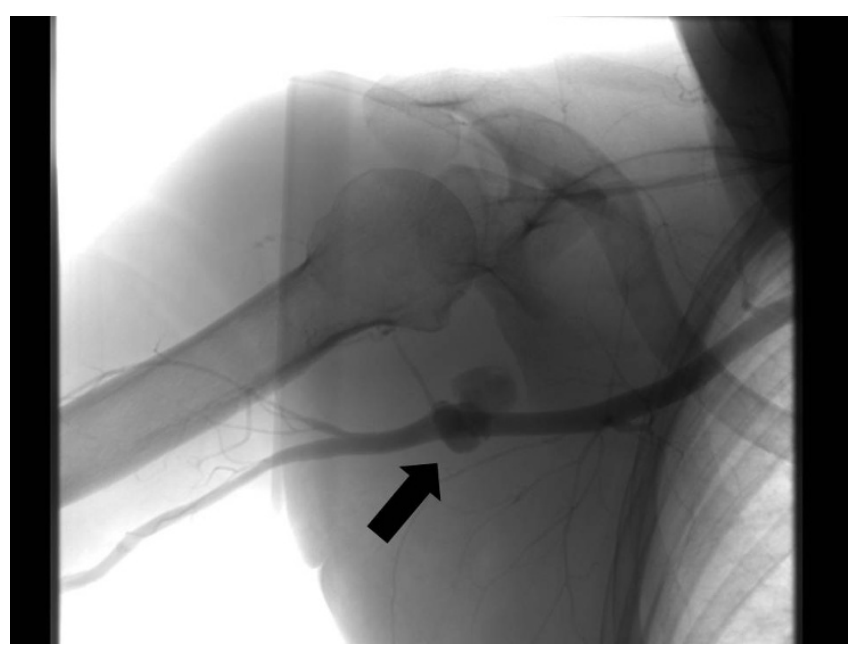

Figure 2

Same case as in figure I. Angiography demonstrates a traumatic axillary artery pseudoaneurysm (arrow). 
Table I: Clinical signs for prediction of an arterial extremity injury.

\begin{tabular}{ll}
\hline "Hard signs" & "Soft signs" \\
\hline Active or pulsatile hemorrhage & Asymmetric extremity blood pressures \\
Pulsatile or expanding hematoma & Stable and non-pulsatile hematoma \\
Clinical signs of limb ischemia & Proximity of wound to a major vessel \\
Diminished or absent pulses & Peripheral neurological deficit \\
Bruit or thrill, suggesting AV-fistula & Presence of shock/hypotension \\
\hline
\end{tabular}

The presence of a "hard sign" of an arterial injury warrants an immediate surgical exploration with the option of an on-table angiography. In contrast, the "soft signs" are less specific in predicting a significant arterial extremity injury. In exclusive presence of a "soft sign", such as an asymmetric anklebrachial-index, the recommended further diagnostic workup includes an angiography or CT-angiography.

successfully reduced upon first attempt under conscious sedation in the ED (Fig. 4B).

After closed reduction, the radial artery pulse was faintly palpable, while Doppler signals were robust. The arm-arm arterial index was found to be pathological, with a value of 0.7. The patrient's left hand continued to appear well perfused with a recapillarisation time of $<2$ seconds. A CT-

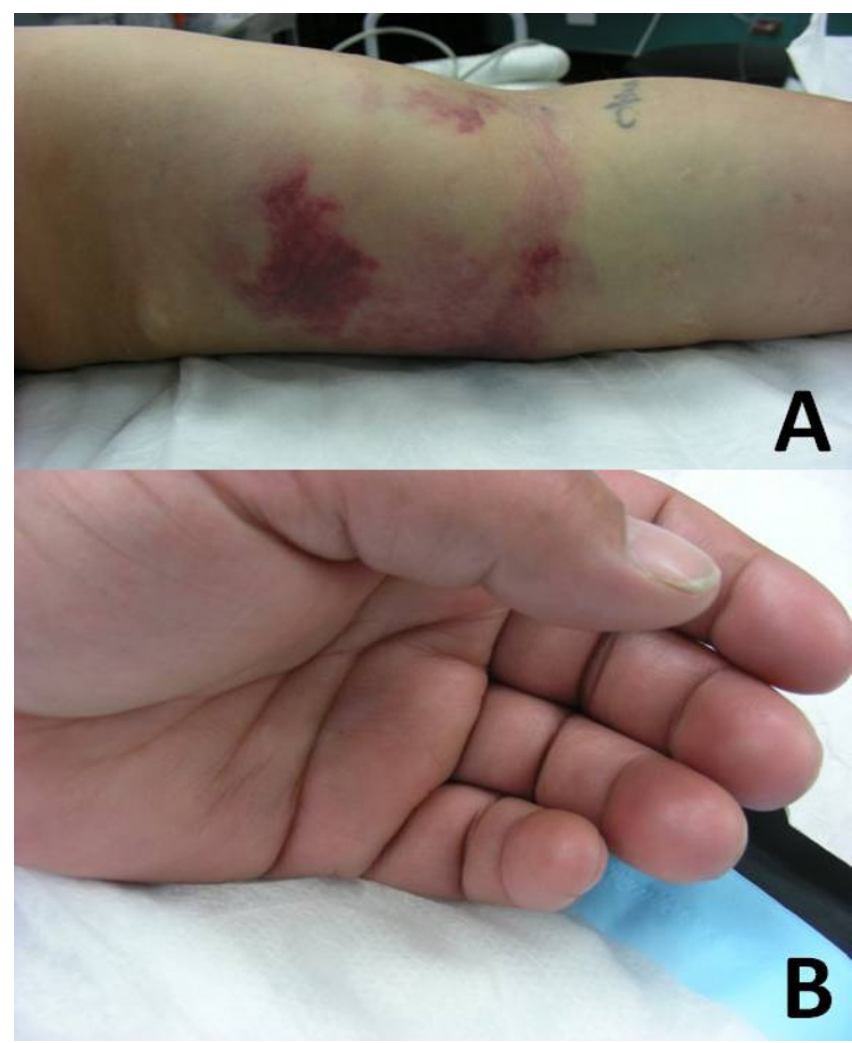

\section{Figure 3}

Case demonstration of a 38-year-old right hand dominant woman who sustained a twisting injury to her left arm during an assault. Clinically, her left elbow showed ecchymosis on the medial side (panel A). Her ipsilaterla hand remained well perfused (panel $B$ ), with a strong radialis pulse and a normal capillary refill, despite the presence of a significant arterial injury. angiography was ordered with concern for arterial injury and revealed an abrupted contrast flow at the level of the elbow, with collateral reconstitution of vascular flow in the forearm (Fig. 5, arrow). The patient was taken emergently to the OR for exploration of the antecubital fossa, revealing a traction-avulsion injury of $5 \mathrm{~cm}$ length at the level of the brachial artery proximal to the bifurcation (Fig. 6). In addition, the anterior joint capsule was found to be completely torn. Arterial repair was performed by interpositional reverse saphenous vein grafting, which reestablished a palpable radial artery pulse. Given the absence of forearm ischemia prior to the repair, as well as soft forearm compartments intraoperatively, the decision was made not to perform a forearm fasciotomy. The arm was placed in a posterior splint until the wound was healed, and the patient had an uneventful postoperative course at follow-up in orthopedic clinic.

\section{Discussion}

Traumatic injuries to the axillary and brachial arteries remain rare, representing $15-20 \%$ of arterial injuries to the upper limb [4]. Approximately $6 \%$ of these injuries are attributable to blunt trauma, with the majority occurring in the setting of fracture-dislocations. Less than $1 \%$ of vascular injuries to the upper extremity are associated with a traumatic dislocation alone [1]. Elderly patients appear more susceptible to vascular injuries, with the majority of reported cases occurring in patients over the age of 50 [3].

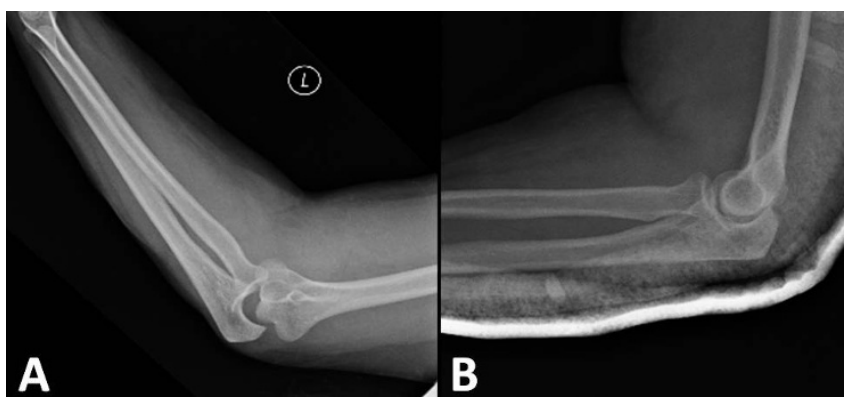

Figure 4

Same case as in figure 3. X-rays before (panel A) and after (panel B) closed reduction of a left elbow dislocation. 


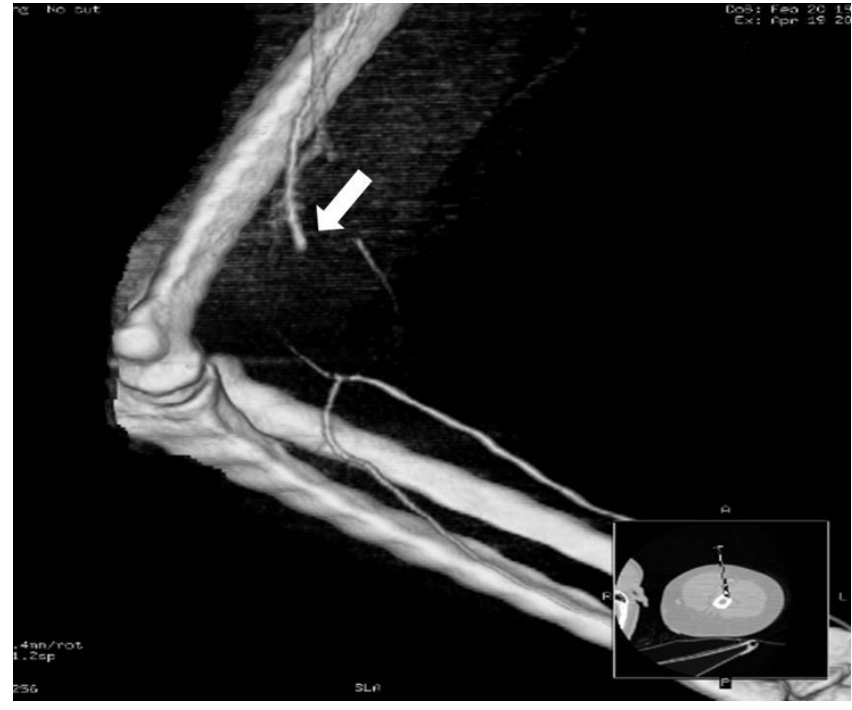

Figure 5

Same case as in figures 3, 4. CT-angiography with 3D-reconstruction demonstrating a 4 to $5 \mathrm{~cm}$ long brachial artery laceration at the elbow (arrow) with reconstitution of forearm vessel flow via collateral perfusion.

Interestingly, up to a third of all patients have a history of previous joint dislocations, suggesting arterial incarceration in scar tissue, which may render the vessel more susceptible to injury during a subsequent dislocation [5].

Several potential mechanisms relating to the particular regional anatomy have been postulated which may account for upper extremity vascular injuries. The axillary artery is typically divided into three segments relative to its relationship with the pectoralis minor muscle. The third segment - defined as the portion distal to the lower

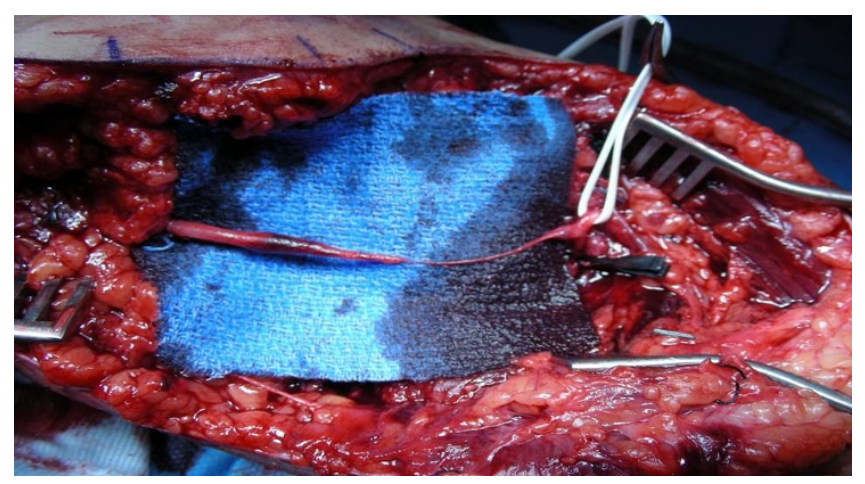

\section{Figure 6}

Same case as in figures $3,4,5$. The intraoperative finding correlates to preoperative CT-angiography, revealing a brachial artery traction injury of about $5 \mathrm{~cm}$ length, located proximal to the bifurcation. edge of the pectoralis minor - appears to be most frequently injured (86\%) [6]. Adoriasio [4] and Milton [7] independently proposed a mechanism by which the axillary artery is exposed to direct injury by the dislocating humeral head, given its relatively fixed anatomical position between the subscapular and humeral circumflex arteries. Multiple authors have additionally proposed a mechanism by which the pectoralis minor muscle acts as fulcrum for the artery, thus enabling a vascular injury by kinking, shearing or compression $[3,6,8,9]$. Although axillary artery injuries are fairly common, fewer than 50 cases related to anterior shoulder dislocations have been reported in the literature, to our knowledge [3,4,10-20].

A major contributing factor for brachial artery injuries at the elbow region is related to a vascular entrapment underneath the lacertus fibrosus in the antecubital fossa. This anatomical relation explains the high incidence of brachial artery injuries proximal to the bifurcation, due to the relative immobility of the artery which prohibits a longitudinal excursion to compensate for forearm rotation about the elbow secondary to elbow dislocations and distal humerus fractures [21]. The elbow has a circumferential "network" of collaterals which feed the radial and ulnar recurrent and interosseus vessels, even in the absence of brachial artery flow. This circumstance explains the relative success of the historical practice of ligation of brachial and/or radial and ulnar arteries in elbow dislocations performed to control posttraumatic bleeding intraoperatively [22].

A pathognomonic "triad" has been described to diagnose vascular lesions in shoulder dislocations, consisting of anterior shoulder dislocation, expanding axillary hematoma and diminished peripheral pulse [3]. Similarly, in closed elbow dislocations, the absence of a radial pulse has been noted to be main predicting factor of an arterial injury [23]. As outlined by the two representative cases in the present paper, the reliance on peripheral pulses alone can be misleading. Sparks et al. described 30 patients with absent peripheral pulses and clinical signs of ischemia, of which only 12 cases were found to have arterial injuries by angiography [1]. On the other hand, palpable distal pulses or pulses detected by Doppler ultrasound may be present even in the instance of complete arterial disruption, due to abundant collateral flow [24,25]. Therefore, the physical exam alone is generally regarded as inadequate for diagnosis of peripheral vascular injury in extremity trauma and has been shown to be a poor predictor of arterial injuries [26-28]. In fact, the "classic" signs of arterial insufficiency may be absent in up to $40 \%$ of patients with upper extremity joint dislocations $[1,29]$. Clinical signs of arterial injury have been stratified based on their predictive value into "hard" and "soft" signs (table 1). The presence of a "hard" sign of vascular injury 
mandates an immediate surgical exploration and vascular repair [26,30-32]. In contrast, clinical "soft" signs (table 1) are much less specific in the diagnosis of a significant arterial injury, and have been found to lack an adequate predictive value $[26,33]$.

Management strategies for patients with vascular injuries have gradually changed over time. During wartimes, a protocol of operative exploration was advocated based on the proximity of injury alone. This concept was abandoned when it became apparent that such a paradigm was not transferable to low-velocity civilian injuries due a low efficiency $[32,34,35]$. In the 1970's and 80's, arteriography became the "gold standard", and was abandoned more recently, due to invasive risks of iatrogenic complications and the observation that the angiographic screening rarely led to a change in patient managemen [33,34,36-41]. Doppler ultrasound was demonstrated to be an effective diagnostic tool, albeit its sensitivity being highly operator-dependent $[30,42,43]$. More recently, the "arterial pressure index" (API) - also described as the "ankle-brachial index" (ABI) or the "ankle-arm index" (AAI) - has become a new standard as a screening tool in the potentially vascular injured limb $[39,41]$. The API is performed by placing a blood pressure cuff just above the ankle or wrist of the injured limb and the systolic pressure is determined by Doppler probe at the respective dorsalis pedis or radial artery. Identical measurement is performed on an uninjured limb and the API is calculated by dividing the systolic pressure in the injured limb by the systolic pressure in the uninjured limb. This tool has been validated in the setting of penetrating and blunt extremity injuries $[39,41,44]$. An API value of $<0.9$ was found to have a sensitivity of $95 \%$ and specificity of $97 \%$ for a major arterial extremity injury [41]. A different study on blunt orthopaedic extremity injuries described the negative predictive value of $100 \%$ for an API $>0.9$ to exclude an arterial injury [44]. In the present paper, only one of two cases had a pathological API of 0.7, while the first patient described in this report here had a misleading API of 1.1, suggesting the absence of an arterial injury. In recent years, CT-angiography (CT-A) has come to play an increasing role in diagnosing suspected peripheral artery injuries. Compared to traditional angiography, as the previous "gold standard", modern CT-A using multislice fine resolution technique has been shown to be less invasive, while yielding a similar diagnostic sensitivity and a more widespread availabilty in the acute workup of trauma patients [45].

Multiple treatment options have been described for arterial injuries associated with extremity trauma. Case reports describe successful outcomes using endovascular techniques employing thrombolysis and stent placement [13]. However, most authors agree that the most adequate treatment modality remains in the surgical exploration with the intraoperative option of a thrombectomy, endto-end anastamosis, saphenous vein graft or prosthetic allograft, with ligation of avulsed collaterals [1]. Prophylactic forearm fasciotomies should be performed in all ischemic limbs due to the high risk of postoperative compartment syndrome secondary to reconstitution of arterial flow, leading to ischemia/reperfusion syndrome.

Unfortunately, until present, there is no established or putative algorithm available which may allow the straight-forward clinical work-up for discrimination and identification of those rare patients who sustained a significant vascular injury after minor blunt upper extremity trauma. Obviously, a full work-up by CT-angiography for every single patient presenting to the emergency department for a traumatic shoulder or elbow dislocation is neither feasible, nor cost-effective. Thus, the emergency physician in charge of these patients in the first place must have a high level of suspicion, in conjunction with the knowledge on the "hard signs" of vascular injuries, as outlined in table 1 . While common clinical knowledge implies that a significant vascular injury may require the history of either a high-energy blunt trauma, or a penetrating trauma mechanism, as a prerequisite, we clearly dismiss this notion in the present paper. Key to success is the awareness of potentially detrimental vascular injuries in minor upper extremity trauma, combined with the knowledge of "hard clinical signs" of vascular injury which will mandate immediate further work-up, with a high likelihood of the need for surgical intervention.

\section{Conclusion}

Vascular injuries in low energy trauma are rare and are easily missed. A high level of suspicion, in conjunction with the knowledge of sensitive and specific clinical signs, is paramount for an accurate and timely diagnosis. A thorough physical exam, including determination of the API, is crucial in the early assessment of a patient with concern for a vascular extremity injury. Based on the presence or absence of "hard" clinical signs of arterial injury, an early indication must be placed for immediate surgical exploration versus additional diagnostic interventions, such as an arteriography or CT-A. In contrast, simple observation represents the prerequisite for a detrimental outcome, since time is of the essence in recognition and management of these rare injuries with a potential for high morbidity and mortality.

\section{Competing interests}

The authors declare that they have no competing interests.

\section{Authors' contributions}

JTB and KI wrote the first draft of the manuscript. WLB and PFS revised the manuscript and performed the final 
editing. KI and PFS provided the two clinical case examples. All authors read and approved the final version of the manuscript.

\section{Consent}

Written informed consent was obtained by the two patients presented in this paper for publication of their individual case reports.

\section{References}

I. Sparks SR, DeLaRosa J, Bergan J], Hoyt DB, Owens EL: Arterial injury in uncomplicated upper extremity dislocations. Ann Vasc Surg 2000, I4(2): I 10-II3.

2. Guibe M: Des lesions des vaisseaux de l'aisselle qui compliquant les luxation de l'epaule. Rev Chir Orthop Reparatrice Appar Mot I9II, 44:582.

3. Kelley SP, Hinsche AF, Hossain JF: Axillary artery transection following anterior shoulder dislocation: classical presentation and current concepts. Injury 2004, 35( I I): I I 28-I I32.

4. Adoriasio RVE, Sgarbi G: Arterial injury of the axilla, an unusual case after blunt trauma of the shoulder. J Trauma 1996, 4I:754-756.

5. Jardon OM, Hood LT, Lynch RD: Complete avulsion of the axillary artery as a complication of shoulder dislocation. J Bone Joint Surg Am 1973, 55(I): 189-192.

6. Gates JD, Knox JB: Axillary artery injuries secondary to anterior dislocation of the shoulder. J Trauma I995, 39(3):58|-583.

7. Milton GW: The circumflex nerve and dislocation of the shoulder. Br J Phys Med I954, I 7(6): I36-138.

8. Brown FW, Navigato W]: Rupture of the axillary artery and brachial plexus palsy associated with anterior dislocation of the shoulder. Report of a case with successful vascular repair. Clin Orthop Relat Res 1968, 60:195-199.

9. Gibson J: Rupture of the axillary artery. J Bone Joint Surg Br 1962 44(B): I I 6.

10. Maweja S, Sakalihasan N, Van Damme H, Limet R: Axillary artery injury secondary to anterior shoulder dislocation: report of two cases. Acta Chir Belg 2002, I02(3):|87-I9|.

II. Onyeka W: Anterior shoulder dislocation: an unusual complication. Emerg Med J 2002, I9(4):367-368.

I2. Julia J, Lozano P, Gomez F, Corominas C: Traumatic pseudoaneurysm of the axillary artery following anterior dislocation of the shoulder. Case report. J Cardiovasc Surg (Torino) 1998, 39(2): 167-169.

13. Zanchetta M, Rigatelli G, Dimopoulos K, Pedon L, Zennaro M, Maiolino $P$ : Endoluminal repair of axillary artery and vein rupture after reduction of shoulder dislocation. A case report. Minerva Cardioangiol 2002, 50(I):69-73.

14. Popescu D, Fernandez-Valencia JA, Combalia A: Axillary arterial thrombosis secondary to anterior shoulder dislocation. Acto Orthop Belg 2006, 72(5):637-640.

15. Razif MA, Rajasingam V: Anterior shoulder dislocation with axillary artery and nerve injury. Med J Malaysia 2002, 57(4):496-498.

16. Allie B, Kilroy DA, Riding G, Summers C: Rupture of axillary artery and neuropraxis as complications of recurrent traumatic shoulder dislocation: case report. Eur J Emerg Med 2005, | 2(3): | $2|-| 23$.

17. Stahnke M, Duddy M]: Endovascular repair of a traumatic axillary pseudoaneurysm following anterior shoulder dislocation. Cardiovasc Intervent Radiol 2006, 29(2):298-30I.

18. Helm AT, Watson JS: Compression of the brachial plexus in a patient with false aneurysm of the axillary artery as a result of anterior shoulder dislocation. J Shoulder Elbow Surg 2002 I I(3):278-279.

19. Emadian SM, Lee WW: Axillary artery pseudoaneurysm and axillary nerve palsy: delayed sequelae of anterior shoulder dislocation. Am J Emerg Med 1996, I4(I): I08-109.

20. Orecchia PM, Calcagno D, Razzino RA: Ruptured axillary pseudoaneurysm from chronic shoulder dislocation. J Vasc Surg 1996, 24(3):499-500.

21. Marcheix B, Chaufour X, Ayel J, Hollington L, Mansat P, Barret A, Bossavy JP: Transection of the brachial artery after closed posterior elbow dislocation. J Vasc Surg 2005, 42(6): I 230-I 232.
22. Eliason ED, Brown RB: Posterior dislocation at the elbow with rupture of the radial and ulnar arteries. Ann Surg 1937, 106: IIII-III5

23. Endean ED, Veldenz HC, Schwarcz TH, Hyde GL: Recognition of arterial injury in elbow dislocation. J Vasc Surg 1992, I 6(3):402-406.

24. Drury JK, Scullion JE: Vascular complications of anterior dislocation of the shoulder. BrJ Surg 1980, 67(8):579-58I.

25. Gugenheim S, Sanders RJ: Axillary artery rupture caused by shoulder dislocation. Surgery 1 984, 95(I):55-58

26. Frykberg ER, Dennis JW, Bishop K, Laneve L, Alexander RH: The reliability of physical examination in the evaluation of penetrating extremity trauma for vascular injury: results at one year. J Trauma I99I, 3 I (4):502-5II.

27. Perry MO, Thal ER, Shires GT: Management of arterial injuries. Ann Surg 197I, I 73(3):403-408.

28. Graves M, Cole PA: Diagnosis of peripheral vascular injury in extremity trauma. Orthopedics 2006, 29(I):35-37.

29. Cikrit DF, Dalsing MC, Bryant BJ, Lalka SG, Sawchuk AP, Schulz JE: An experience with upper-extremity vascular trauma. Am J Surg 1990, 160(2):229-233

30. Anderson RJ, Hobson RW 2nd, Padberg FT Jr, Swan KG, Lee BC, Jamil Z, Breitbart G, Manno J: Penetrating extremity trauma: identification of patients at high-risk requiring arteriography. J Vasc Surg 1990, I I (4):544-548.

31. Anderson RJ, Hobson RW 2nd, Lee BC, Manno J, Swan KG, Padberg FT Jr, Jamil Z, Cambria RA, Breitbart GB: Reduced dependency on arteriography for penetrating extremity trauma: influence of wound location and noninvasive vascular studies. J Trauma 1990, 30(9): 1059-1063. discussion 1063-1055.

32. Turcotte JK, Towne JB, Bernhard VM: Is arteriography necessary in the management of vascular trauma of the extremities? Surgery 1978, 84(4):557-562.

33. Frykberg ER, Vines FS, Alexander RH: The natural history of clinically occult arterial injuries: a prospective evaluation. J Trauma 1989, 29(5):577-583.

34. Rose SC, Moore EE: Trauma angiography: the use of clinica findings to improve patient selection and case preparation. J Trauma 1988, 28(2):240-245

35. Geuder JW, Hobson RW 2nd, Padberg FT Jr, Lynch TG, Lee BC, Jamil $Z$ : The role of contrast arteriography in suspected arterial injuries of the extremities. Am Surg 1985, 5 I (2):89-93.

36. Bunt TJ, Malone JM, Moody M, Davidson J, Karpman R: Frequency of vascular injury with blunt trauma-induced extremity injury. Am / Surg 1990, I 60(2):226-228.

37. Weaver FA, Yellin AE, Bauer M, Oberg J, Ghalambor N, Emmanuel RP, Applebaum RM, Pentecost MJ, Shorr RM: Is arterial proximity a valid indication for arteriography in penetrating extremity trauma? A prospective analysis. Arch Surg 1990, I 25(10): | 256-| 260.

38. Hughes CW: Arterial repair during the Korean war. Ann Surg 1958, I47(4):555-56।.

39. Johansen K, Lynch K, Paun M, Copass M: Non-invasive vascular tests reliably exclude occult arterial trauma in injured extremities. J Trauma I99|, 3 I(4):5 I5-519. discussion 519-522.

40. Kendall RW, Taylor DC, Salvian AJ, O'Brien PJ: The role of arteriography in assessing vascular injuries associated with dislocations of the knee. J Trauma 1993, 35(6):875-878.

4I. Lynch K, Johansen K: Can Doppler pressure measurement replace "exclusion" arteriography in the diagnosis of occult extremity arterial trauma? Ann Surg 1991, 2 I 4(6):737-74 I.

42. Meissner $M$, Paun $M$, Johansen $K$ : Duplex scanning for arterial trauma. Am J Surg I99I, I 6 I (5):552-555.

43. Panetta TF, Hunt JP, Buechter KJ, Pottmeyer A, Batti JS: Duplex ultrasonography versus arteriography in the diagnosis of arterial injury: an experimental study. J Trauma 1992, 33(4):627-635, discussion 635-626.

44. Mills WJ, Barei DP, McNair P: The value of the ankle-brachial index for diagnosing arterial injury after knee dislocation: a prospective study. J Trauma 2004, 56(6): | 26|-|265.

45. Peng PD, Spain DA, Tataria M, Hellinger JC, Rubin GD, Brundage SI: CT angiography effectively evaluates extremity vascular trauma. Am Surg 2008, 74(2): I03-107. 